\begin{tabular}{|c|c|c|c|c|c|c|c|c|c|c|c|c|c|c|c|c|}
\hline$E$ & $\subset$ & $\bullet$ & $N$ & $\odot$ & $M$ & I & 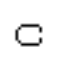 & $s$ & $\boxminus$ & $\sqcup$ & L & L & $E$ & $\mathrm{~T}$ & I & $N$ \\
\hline
\end{tabular}

\title{
A cooperative game for siting noxious facilities: theory and experimental design
}

\author{
Marchetti Nicolas \\ LAMETA, UMR 5474
}

\author{
Serra Daniel \\ LAMETA, UMR 5474
}

\begin{abstract}
The siting of noxious facilities is usually a reason for conflict: as a society we want them, but as individuals (and often as communities) we do not want them close by. Faced with this problem economists have used several methods such as lotteries, auctions or insurance policies. However, all those mechanisms have theoretical shortcomings. Therefore, we propose a new approach based on voluntary exchange. In order to reduce transaction costs, we introduce an arbitrator that proposes surplus distribution and a host community. The main question in this paper is to determine which distributions it has to propose to quickly reach an agreement. To this end, a new asymmetric cooperative game is constructed and three classical solution concept are studied after adaptation to the asymmetric context of the game. Finally, we explore the predictive power of these solutions by implementing laboratory bargaining experiments.
\end{abstract}

Citation: Nicolas, Marchetti and Serra Daniel, (2003) "A cooperative game for siting noxious facilities: theory and experimental design." Economics Bulletin, Vol. 3, No. 22 pp. 1-8

Submitted: June 23, 2003. Accepted: September 11, 2003.

URL: http://www.economicsbulletin.com/2003/volume3/EB-03C70016A.pdf 


\section{Introduction}

The siting of noxious facilities ${ }^{1}$ is usually a reason for conflict illustrated perfectly by what the Anglo-Saxons call the NIMBY (Not In My BackYard) syndrome: everyone knows the facility is necessary but no one is willing to host it. Faced with this problem economists and operations researchers have used several methods such as lotteries (Kunreuther and Portney [1991], Sullivan [1990]), auctions (Kunreuther and Kleindorfer [1986], Kunreuther and al. [1987], O'Sullivan [1993]) or insurance policies (Goetze [1982]). However, all those mechanisms have theoretical shortcomings.

Thus, in this paper, we propose a new mechanism, based on voluntary exchange, for siting noxious facilities when few jurisdictions ${ }^{2}$ negotiate and when each jurisdiction takes reponsibility for the waste generated within its boundaries. Under these conditions, we can suppose (i) that each jurisdiction has complete information on the costs of a facility in its jurisdiction or in other potential host jurisdictions (Catin [1985]) and (ii) that property rights are clear or well defined. The Coase Theorem asserts that if there are no transaction costs and if property rights are clearly defined, the economy will achieve efficiency through voluntary negotiations between the involved agents even when there are externalities (Coase [1960]). Because of the complete information, the only transaction costs are delays and it is well known that negative externalities may cause delay in negotiation (Jehiel and Moldovanu [1995]). So, in order to reduce these potential delays, we introduce an arbitrator that proposes surplus distribution and a host community. But which surplus distributions does the arbitrator have to propose? That is the main question in this paper.

To answer this question we propose to revise the traditional structure of cooperative games. Section 2 presents the new cooperative game (the coalition values of the cooperation depend not only on the membership factor, the structure coalition, but also on who hosts the facility). In section 3, we generalize three classical solution concepts: the Shapley value, the nucleolus and the core. We explore in section 4 the predictive power of these solutions by implementing laboratory bargaining experiments. Finally, section 5 concludes this paper.

\section{The modeling of the siting problem}

\section{1 hypotheses and example}

To structure the siting problem with characteristic functions three hypotheses are made as follows. (i) Each jurisdiction takes reponsibility for the waste generated within its boundaries. (ii) The equipment market should be common knowledge. (iii) There are increasing economic return to scale for hazardous facilities. In this case, collective incentives for jurisdictions to cooperate to share a facility occur naturally and automatically. The scale economies are the key to cooperation. If there are not present, the problem of siting is simple: each one its own facility.

The following example illustrates, in a simple way, the siting problem submitted to analysis. Three French neighbouring towns, $a, b, c$ produce household garbage. Each city can build its own incinerator or can cooperate to share a big incinerator. Table (11.) furnishes the costs with respect to all of the possible situations. For example, if city $a$ and city $b$ construct a single facility sited in $a$, the cost for them is - 137 jointly and if it is sited in city $b$ the cost for them is only -132 jointly. Note that the geographical and economical differences between the localities create significant variations in costs; furthermore, economies of scale appear. Table (11.) can be charted from the viewpoint of surplus (See table (1r.)). Hence, if $b$ joins $a$ with $a$ as host of the facility, the cost for them is -137 . Compared to their status quo of total cost $-150(=-80+(-70))$, they end up with a surplus of $13(=-137-(-150))$.

\footnotetext{
${ }^{1}$ Trash disposal plants, landfills, hazardous waste facilities and waste incinerators.

${ }^{2} \mathrm{By}$ jurisdictions, we mean communities composed of individuals having the right to make decisions on their own behalf. That is State, region, district or city.
} 
Table 1: The costs and surpluses matrixes

\begin{tabular}{c|ccc}
\hline \multicolumn{3}{c}{ Host city } \\
\hline \hline CoALITION & $a$ & $b$ & $c$ \\
\hline stand alone & -80 & -70 & -133 \\
$a$ and $b$ & -137 & -132 & -133 \\
$a$ and $c$ & -138 & -70 & -157 \\
$b$ and $c$ & -80 & -114 & -137 \\
$a, b$ and $c$ & -176 & -165 & -191 \\
\hline
\end{tabular}

\begin{tabular}{c|ccc}
\hline \multicolumn{3}{c}{ Host city } \\
\hline \hline CoALITION & $a$ & $b$ & $c$ \\
\hline stand alone & 0 & 0 & 0 \\
$a$ and $b$ & 13 & 18 & 0 \\
$a$ and $c$ & 75 & 0 & 56 \\
$b$ and $c$ & 0 & 89 & 66 \\
$a, b$ and $c$ & 107 & 118 & 92 \\
\hline
\end{tabular}

\subsection{Formal approach}

Faced with this surplus matrix, negotiators must choose the host city and the sharing of surplus. In order to reduce the duration of the negotiations, we introduce an arbitrator. He proposes a host city and a sharing of surplus. But which sharing of surplus does the arbitrator have to propose to "quickly" reach an agreement? For Sharing problems, cooperative games provide an operational scheme for conceptualization. But traditional cooperative games only take into account the coalition value due to membership. In our problem, the coalition values could vary and depend on who is the host of the facility. So, it is first necessary to enlarge the possibilities of coalition, taking into account the new factor, called the "host factor". We therefore obtain a characteristic function in the form of:

$$
v^{i}: T=\{(i, C) \mid i \in C, C \subset N\} \rightarrow R^{+}
$$

The function $v^{i}$ is defined in a "cooperation set" $n(n+1)$. By convention, $v^{i}(R)$ represents the surplus of the coalition $R$ when the facility is sited in community $i$. In this context, the payoff of the communities is represented by $X=\left\{x=\left(x_{1} \ldots x_{i} \ldots x_{n}\right), x_{i} \in \mathbb{R}^{+}\right\}$with $\sum_{i=1}^{n} x_{i}=\max _{j \in N} v^{j}(N)$. So, in order to reflect the existence of economies of scale during the construction of the equipment, we impose a specific condition of superadditivity, derived from the condition of the same name in the traditional cooperative game theory:

$$
\max _{i \in R} v^{i}(R)+\max _{j \in S} v^{j}(S) \leq \max _{k \in R \cup S} v^{k}(R \cup S), R \cap S=\emptyset, R, S \subset N
$$

For laboratory bargaining experiments, we use three games. Two asymmetric games (Table 21 .), noted respectively $\left(N, v_{a 66}\right)$ and $\left(N, v_{a 10}\right)$. The index $a$ denotes that the cooperative game is asymmetric because of the explicit taking into account of the host factor. The index 66 of the first game simply corresponds to the value $v^{c}(\{b c\})$ in this game. This value is reduced to 10 in the game $\left(N, v_{a 10}\right)$. This reduction reflects a decrease of the bargaining power of community $c$ in this last game. The third game, $\left(N, v_{s}\right)$, corresponds to a symmetric cooperative game. The "host factor" plays no role whatsoever (Table 2r.).

Table 2: Symmetric and asymmetric games

\begin{tabular}{c|ccc}
\hline & \multicolumn{3}{c}{ Host Community } \\
\hline \hline CoAlition & $a$ & $b$ & $c$ \\
\hline$a$ and $b$ & 13 & 18 & - \\
$a$ and $c$ & 75 & - & 56 \\
$b$ and $c$ & - & 89 & 66 or 10 \\
$a, b$ and $c$ & 107 & 118 & 92 \\
\hline
\end{tabular}

\begin{tabular}{c|c}
\hline COALITION & Value \\
\hline \hline$a$ and $b$ & 18 \\
$a$ and $c$ & 75 \\
$b$ and $c$ & 89 \\
$a, b$ and $c$ & 118 \\
\hline
\end{tabular}




\section{Definition and computation of the solutions}

In this study we consider two solution concepts, the nucleolus (Schmeidler [1969,1994]) and the Shapley value (Shapley [1953], Owen [1995]), as well as the general concept of the core. These concepts must be modified in order to integrate the influence of the "host factor".

\subsection{Generalized nucleolus}

The method used for the computation of the generalized nucleolus can be summarized in the following manner: starting from a set of "cooperation" $T=\{(i, P) \mid i \in P, P \subset N\}$, we note $c(T)=P$ the coalition and $h(T)=i$ the host city inside this coalition. Then define the excess as

$$
e(R, x)=v^{h(R)}(c(R))-x(c(R)), R \in T, x \in X
$$

Where $x(c(R))$ is shorthand for $\sum_{j \in c(R)} x_{j}$. For a payoff $x \in X$, the excess can be used as a measure of the sacrifice (gain) of the members in the coalition $c(R)$ with the host of $i$ if $e(R, x)>0$ (respectively $<0$ ). In this context, an objection of $i$ to $j$ is

$$
S_{i j}(x)=\max _{U}\{e(U, x) \mid U \in T, i=h(U), j \in N \backslash c(U), x \in X\}
$$

$S_{i j}(x)$ is a measure of the dissatisfaction of $i$ to the payoff that $j$ receives. On the other hand, $j$ can exercise a counter-objection against $i$ as

$$
S_{j i}(x)=\max _{V}\{e(V, x) \mid V \in T, i \in N \backslash c(V), j=h(V), x \in X\}
$$

The objection by $i$ is considered justified if $S_{i j}(x)$ is greater than $S_{j i}(x)$. Given the payoff $x$, jurisdiction $i$ 's net demand on all other jurisdictions is therefore

$$
D_{i}(x)=\sum_{j \in N}\left[S_{i j}(x)-S_{j i}(x)\right]
$$

If $D_{i}(x)>0, i$ is underpaid and deserves more compensation. Inversely, if $D_{i}(x)<0, i$ is overpaid. When $D_{i}\left(x^{*}\right)=0, \forall i \in N$, the payoff $x^{*}$ is undefeatable by any subcoaltions and payoffs. In this way, we obtain an equilibrium point qualified as the generalized nucleolus, because it follows the same rules as in defining the nucleolus in the traditional cooperative game theory

$$
N_{a} \equiv\left\{x \in X \mid D_{i}(x)=0, \forall i \in N\right\}
$$

To summarize, the generalization of the nucleolus proposed in this paper is essentially situated at the level of objections and counter-objections: a jurisdiction that exercise an objection must propose a new coalition inside which it will become the host city.

\subsection{Generalized Shapley value}

To calculate the Shapley value in the asymmetric game $\left(N, v_{a 66}\right)$ et $\left(N, v_{a 10}\right)$, we proceed in the same manner as for the traditional Shapley value, but we take into account all possible coalitions. Table 3 is designed to show the step of calculation of $V_{a 66}$ and $V_{a 10}$ (values in brackets). The notations are as follows: $\{a\}^{a} \rightarrow\{a b\}^{a} \rightarrow\{a b c\}^{a}$ represents the coalition formed in the following order $a b c$, with $a$ as host city. The $V_{a}^{i *}$ do not correspond to the Shapley value because their sum is not equal to 118 but to the average of $v^{i}(\{i j k\})$. At the end of the procedure, we are therefore left with the allocation of a payoff equal to the difference between the averages of $v^{i}(\{i j k\})$ and 118. The calculation of the Shapley value being based on the notion of marginal contribution, it therefore seems normal to allocate this sum proportionally to each marginal contribution. 
Table 3: Shapley values in the games $\left(N, v_{a 66}\right)$ and $\left(N, v_{a 10}\right)$

\begin{tabular}{|c|c|c|c|c|c|c|c|}
\hline \multicolumn{5}{|c|}{ Community } & \multicolumn{3}{|c|}{ Community } \\
\hline & $\mathrm{a}$ & $\mathrm{b}$ & $\mathrm{c}$ & & $\bar{a}$ & $\mathrm{~b}$ & c \\
\hline$\{\mathrm{a}\}^{\mathrm{a}} \rightarrow\{\mathrm{ab}\}^{\mathrm{a}} \rightarrow\{\mathrm{abc}\}^{\mathrm{a}}$ & 0 & 13 & 94 & $\left.\Gamma_{\{b}\right\}^{b} \rightarrow\{b c\}^{b} \rightarrow\{b c a\}^{a}$ & 18 & 0 & 89 \\
\hline$\{a\}^{\mathrm{a}} \rightarrow\{\mathrm{ab}\}^{\mathrm{a}} \rightarrow\{\mathrm{abc}\}^{\mathrm{b}}$ & 0 & 13 & 105 & $\{b\}^{b} \rightarrow\{b c\}^{b} \rightarrow\{b c a\}^{b}$ & 29 & 0 & 89 \\
\hline$\{a\}^{\mathrm{a}} \rightarrow\{\mathrm{ab}\}^{\mathrm{a}} \rightarrow\{\mathrm{abc}\}^{\mathrm{c}}$ & 0 & 13 & 79 & $\{b\}^{b} \rightarrow\{b c\}^{b} \rightarrow\{b c a\}^{c}$ & 3 & 0 & 89 \\
\hline$\{a\}^{a} \rightarrow\{a b\}^{b} \rightarrow\{a b c\}^{a}$ & 0 & 18 & 89 & $\{b\}^{b} \rightarrow\{b c\}^{c} \rightarrow\{b c a\}^{b}$ & $41(97)$ & 0 & $66(10)$ \\
\hline$\{\mathrm{a}\}^{\mathrm{a}} \rightarrow\{\mathrm{ab}\}^{\mathrm{b}} \rightarrow\{\mathrm{abc}\}^{\mathrm{b}}$ & 0 & 18 & 100 & $\{b\}^{b} \rightarrow\{b c\}^{c} \rightarrow\{b c a\}^{c}$ & $52(108)$ & 0 & $66(10)$ \\
\hline$\{a\}^{\mathrm{a}} \rightarrow\{\mathrm{ab}\}^{\mathrm{b}} \rightarrow\{\mathrm{abc}\}^{\mathrm{c}}$ & 0 & 18 & 74 & $\{b\}^{b} \rightarrow\{b c\}^{c} \rightarrow\{b c a\}^{a}$ & $26(82)$ & 0 & $66(10)$ \\
\hline$\{\mathrm{a}\}^{\mathrm{a}} \rightarrow\{\mathrm{ac}\}^{\mathrm{a}} \rightarrow\{\mathrm{acb}\}^{\mathrm{a}}$ & 0 & 32 & 75 & $\{c\}^{\mathrm{c}} \rightarrow\{\mathrm{ca}\}^{\mathrm{c}} \rightarrow\{\mathrm{cab}\}^{\mathrm{a}}$ & 56 & 51 & 0 \\
\hline$\{\mathrm{a}\}^{\mathrm{a}} \rightarrow\{\mathrm{ac}\}^{\mathrm{a}} \rightarrow\{\mathrm{acb}\}^{\mathrm{b}}$ & 0 & 43 & 75 & $\{c\}^{\mathrm{c}} \rightarrow\{\mathrm{ca}\}^{\mathrm{c}} \rightarrow\{\mathrm{cab}\}^{\mathrm{b}}$ & 56 & 62 & 0 \\
\hline$\{\mathrm{a}\}^{\mathrm{a}} \rightarrow\{\mathrm{ac}\}^{\mathrm{a}} \rightarrow\{\mathrm{acb}\}^{\mathrm{c}}$ & 0 & 17 & 75 & $\{\mathrm{c}\}^{\mathrm{c}} \rightarrow\{\mathrm{ca}\}^{\mathrm{c}} \rightarrow\{\mathrm{cab}\}^{\mathrm{c}}$ & 56 & 36 & 0 \\
\hline$\{\mathrm{a}\}^{\mathrm{a}} \rightarrow\{\mathrm{ac}\}^{\mathrm{c}} \rightarrow\{\mathrm{acb}\}^{\mathrm{a}}$ & 0 & 51 & 56 & $\{c\}^{\mathrm{c}} \rightarrow\{\mathrm{ca}\}^{\mathrm{a}} \rightarrow\{\mathrm{cab}\}^{\mathrm{a}}$ & 75 & 32 & 0 \\
\hline$\{\mathrm{a}\}^{\mathrm{a}} \rightarrow\{\mathrm{ac}\}^{\mathrm{b}} \rightarrow\{\mathrm{acb}\}^{\mathrm{b}}$ & 0 & 62 & 56 & $\{c\}^{\mathrm{c}} \rightarrow\{\mathrm{ca}\}^{\mathrm{a}} \rightarrow\{\mathrm{cab}\}^{\mathrm{b}}$ & 75 & 43 & 0 \\
\hline$\{\mathrm{a}\}^{\mathrm{a}} \rightarrow\{\mathrm{ac}\}^{\mathrm{c}} \rightarrow\{\mathrm{acb}\}^{\mathrm{c}}$ & 0 & 36 & 56 & $\{c\}^{\mathrm{c}} \rightarrow\{\mathrm{ca}\}^{\mathrm{a}} \rightarrow\{\mathrm{cab}\}^{\mathrm{c}}$ & 75 & 17 & 0 \\
\hline$\{b\}^{b} \rightarrow\{b a\}^{a} \rightarrow\{b a c\}^{a}$ & 13 & 0 & 94 & $\{c\}^{\mathrm{c}} \rightarrow\{\mathrm{cb}\}^{\mathrm{c}} \rightarrow\{\mathrm{cba}\}^{\mathrm{a}}$ & $41(97)$ & $66(10)$ & 0 \\
\hline$\{b\}^{b} \rightarrow\{b a\}^{a} \rightarrow\{b a c\}^{b}$ & 13 & 0 & 105 & $\{c\}^{\mathrm{c}} \rightarrow\{\mathrm{cb}\}^{\mathrm{c}} \rightarrow\{\mathrm{cba}\}^{\mathrm{b}}$ & $52(108)$ & $66(10)$ & 0 \\
\hline$\{b\}^{b} \rightarrow\{b a\}^{a} \rightarrow\{b a c\}^{c}$ & 13 & 0 & 79 & $\{c\}^{\mathrm{c}} \rightarrow\{\mathrm{cb}\}^{\mathrm{c}} \rightarrow\{\mathrm{cba}\}^{\mathrm{c}}$ & $26(82)$ & $66(10)$ & 0 \\
\hline$\{b\}^{b} \rightarrow\{b a\}^{b} \rightarrow\{b a c\}^{a}$ & 18 & 0 & 89 & $\{c\}^{\mathrm{c}} \rightarrow\{\mathrm{cb}\}^{\mathrm{b}} \rightarrow\{\mathrm{cba}\}^{\mathrm{a}}$ & 18 & 89 & 0 \\
\hline$\{\mathrm{b}\}^{\mathrm{b}} \rightarrow\{\mathrm{ba}\}^{\mathrm{b}} \rightarrow\{\mathrm{bac}\}^{\mathrm{b}}$ & 18 & 0 & 100 & $\{c\}^{\mathrm{c}} \rightarrow\{\mathrm{cb}\}^{\mathrm{b}} \rightarrow\{\mathrm{cba}\}^{\mathrm{b}}$ & 29 & 89 & 0 \\
\hline$\{\mathrm{b}\}^{\mathrm{b}} \rightarrow\{\mathrm{ba}\}^{\mathrm{b}} \rightarrow\{\mathrm{bac}\}^{\mathrm{c}}$ & 18 & $\underline{0}$ & 74 & $\{c\}^{\mathrm{c}} \rightarrow\{\mathrm{cb}\}^{\mathrm{b}} \rightarrow\{\mathrm{cba}\}^{\mathrm{c}}$ & 3 & 89 & 0 \\
\hline & & & & Mean $=V_{a 66}^{i} *$ & 22,89 & 28,89 & 53,83 \\
\hline & & & & Mean $=V_{a 10}{ }^{i} *$ & 32,22 & 24,22 & 49,22 \\
\hline
\end{tabular}

\subsection{Core, inner core and outer core}

We know that a division is called "coalitionally rational" if, and only if, the sum of the payoffs for any coalition is no less than the coalition value, a term coined by Aumann and Maschler (1964). This concept is also referred to as the "core" noted $\mathcal{C}$

$$
x \in \mathcal{C} \text { if } v(S) \leq \sum_{j \in S} x_{j}, \forall S \subseteq N
$$

In a traditional game, $v(S)$ is unique and this concept can be applied without difficulty. However, when the value of $v(S)$ is not unique this concept must be modified as follows

$x \in \mathcal{I C}$ if $\sum_{j \in S} x_{j} \geq \max _{i \in S} v^{i}(S), \forall S \subseteq N$ and $x \in \mathcal{O C}$ if $\left\{\begin{array}{l}\sum_{j \in S} x_{j} \geq \min _{i \in S} v^{i}(S), \forall S \subset N \\ \sum_{j \in N} x_{j} \geq \max _{i \in N} v^{i}(N)\end{array}\right.$

Where $\mathcal{I C}$ is the "inner core" and $\mathcal{O C}$ the "outer core". The inner core is by definition a smaller set of solutions than the outer core. Effectively, in the inner core, the communities form an optimal coalition, they look for a location which permits the receipt of a maximum surplus. In the outer core the communities are content with a payoff sum superior to the value of the minimal coalition, that is the one for which the surplus is the lowest.

\subsection{Numerical applications}

We have made a presentation of the three concepts that are experimentally tested in this study. Applying these definitions to the three games presented in section 2 leads to the vectors presented in table 4 . 
Table 4: Predictions by the three solution concepts

\begin{tabular}{c|ccc|cccc|cccc}
\hline \multicolumn{1}{c}{$\left(N, v_{s}\right)$} & \multicolumn{1}{c}{$\left(N, v_{a 66}\right)$} & \multicolumn{6}{c}{$\left(N, v_{a 10}\right)$} \\
\hline \hline $\begin{array}{c}\text { Solution } \\
\text { concepts } \rightarrow\end{array}$ & $V_{s}$ & $N_{s}$ & $C$ & $V_{a 66}$ & $N_{a 66}$ & $I C_{a 66}$ & $O C_{a 66}$ & $V_{a 10}$ & $N_{a 10}$ & $I C_{a 10}$ & $O C_{a l 0}$ \\
\hline$a$ & 25 & 11 & $\leq 29$ & 26 & 17 & $\leq 29$ & $\leq 52$ & 36 & 36 & $\leq 29$ & $\leq 108$ \\
$b$ & 32 & 25 & $\leq 43$ & 32 & 31 & $\leq 43$ & $\leq 62$ & 27 & 31 & $\leq 43$ & $\leq 62$ \\
$c$ & 61 & 82 & $\leq 100$ & 60 & 70 & $\leq 100$ & $\leq 105$ & 55 & 51 & $\leq 100$ & $\leq 105$ \\
\hline
\end{tabular}

\section{Experimental design and results}

Which surplus distribution does the arbitrator have to propose? Since we do not have real cases to test the predictions and real cases may not have the controls we need, laboratory bargaining experiments are thus used to this end.

\subsection{Hypotheses and protocol description}

We test six hypotheses:

1. Are the decisions made by the subjects similar in an asymmetric or symmetric game?

2. Do the subjects use in a relevant way the information given by the asymmetric game?

3. Should one have to modify the nucleolus?

4. Should one have to modify the Shapley value?

5. Which solution reflects in the best way the subject behavior in the symmetric game: the nucleolus or the Shapley value?

6 . Which solution reflects in the best way the subject behavior in the asymmetric game: the nucleolus or the Shapley value?

One laboratory bargaining experiment was used to test these six hypotheses. Thirty-six subjects (in four groups of nine) took part in this experimental bargaining experiment. Subjects were students (Economics and Arts) that had no experience in game theory. On average, the experiments were finished within an hour. Subjects were told that their reward depended on their performance in the negotiation of how benefits would be shared. Every point each subject received was worth $\$ 0,15$. In addition, subjects were paid a fixed payement of $\$ 4$ for participating in the negotiation. The following stages describe the procedure of each session which included two phases: an introductory phase and the experimental phase.

Introductory phase: the nine subjects enter the room and each draws an identification number randomly. They go to the table on which their number is marked. On this table they find a form including a detailed description of the problem, an example of the surplus matrix, a bargaining simulation, an awareness of the fact that there exists some payoffs in which everyone is better off (that is the core), and the rules of reward which are applied. When the subjects have read for ten minutes, the experimenter writes an example on the blackboard and subjects are invited to offer a payoff allocation to the three cities. The experimenter answers questions.

Experimental phase: subjects gather at the tables in groups of three for face to face negotiation. On each of the three tables they find a description of the game rules as well as the explanations necessary for the progress of the experiment. Subjects participate in the three scenarios $\left(\left(N, v_{a 10}\right),\left(N, v_{a 66}\right)\right.$ and $\left.\left(N, v_{s}\right)\right)$; each one consists of three games, because subjects represent randomly each city $a, b$ and $c$. At the end of the session we therefore obtain 27 payoff allocations. Subjects have five minutes to agree on who hosts the facility and how to share the surplus. If after five minutes there is no agreement, subjects receive no reward. Once subjects have finished the three games of scenario $\left(N, v_{a 10}\right)$, they pass on to scenario $\left(N, v_{a 66}\right)$ and next to scenario $\left(N, v_{s}\right)$. Subjects change negotiating tables each time 
the scenario change, so that they negotiate with different partners every time. The groups for the first scenario are : $(1,2,3)(4,5,6)(7,8,9)$, for the second scenario : $(1,4,7)(2,5,8)(3,6,9)$, and for the third scenario : $(1,6,8)(2,4,9)(3,5,7)$. At the end of the session each subject is paid anonymously in cash.

\subsection{Experimental results}

Before tackling nonparametric tests let us develop briefly three remarks on data obtained. Firstly, 8 percent of the coalitions are different from the grand optimal coalition (i.e. $\left.v^{b}(\{a b c\})\right)$. We do not include these subcoalition allocations in our statistical analysis because the arbitrator has to propose an efficient division of the surplus. Secondly, 63 percent of the vectors do not belong to the inner core. At least two reasons can be produced for explaining this fairly large proportion of allocations outside the inner core: either the individuals are incapable of understanding or calculating the inner core (bounded cognitive or instrumental capacities), either factors, such as altruism or reciprocity, influence the individuals' behavior. This second hypothesis is the most plausible. Indeed, the core was presented during the introductory phase. Thirdly, when the grand optimal coalition is formed there are no solutions outside of the outer core.

In order to test the six hypotheses, we realized nonparametric tests (Siegel and Castellan (1988)). We use the Mann-Withney Rank-Sum test when we analyse two independent samples (hypotheses 1 and 2) and we use the Wilcoxon Signed-Rank test for paired data (hypotheses 3 to 6$)$.

Globally we can then advance the following experimental evidence: (1) The introduction of the host factor in the framing of the siting problem affects the behavior of each individual. (2) The nucleolus and the Shapley value must be generalized to allow an accurate prediction. (3) The Shapley value supplies far better predictions than the nucleolus in the traditional symmetric game. (4) The generalized Shapley value supplies better predictions than the generalized nucleolus in the asymmetric games. (5) The subjects perceive a decreasing of the negotiating power of community $c$ when changing from a symmetric game to an asymmetric game. (6) The negotiating procedure often leads to observed solutions outside the inner core, but as foreseen, there are no solutions exterior to the outer core.

\section{Summary and conclusion}

The main purpose of the present paper is to design a mechanism to overcome the impasses that often arise in the process of siting hazardous facilities. However, in voluntary exchange mechanism transaction costs prevent the negotiations from reaching the optimum. More particularly, siting procedures take time. To reduce transactions costs we introduce an arbitrator who proposes surplus distributions. The main goal of this paper is to determine which distributions it has to propose to reach an agreement. To this end, a new cooperative game is constructed to facilitate this cooperation. The game takes into account the selection of a host, which is the essential concern in siting, but also the coalition structure, the only factor considered in traditional cooperative game.

Two bargaining solutions are proposed for the game which yield the optimal site and the transfer payments among participating communities: Shapley value and nucleolus. These two classical solution concepts are studied after adaptation to the asymmetric context of the game. Furthermore the experimental results indicate that the presentation of the siting problem in its different formats (asymmetric or symmetric cooperative games) are different. In general the results are significantly different. Moreover, the experimental results show that the predictive power of the generalized Shapley value (more centred on efficiency) is better than the nucleolus (more focused on the equity) by a significant margin. The arbitrator must propose a generalized Shapley value solution to quickly reach an optimal agreement and thus 
overcome the NIMBY syndrome.

This paper identifies several opportunities for further works on mechanisms to facilitate the siting of noxious facilities. The first option is to generalize new solution concepts and maybe assume that players are not "rational". A second option is to explore the effects of the mechanism when participation is irrational for some cities. Moreover, in this paper, we suppose that communities each have complete information on the costs of a facility in their jurisdiction or in other potential host jurisdictions. This hypothesis is realistic when few jurisdictions negotiate (Catin (1985)). But in the real world many jurisdictions can participe in such negotiations. So, a final option for extending the analysis is to consider that jurisdictions each have incomplete information on the cost of a facility in other potential host jurisdictions.

\section{REFERENCES}

Aumann, R.J. and Maschler M. (1964), The bargaining set for cooperative games, in M. Dresher, L., Shapley S. and Tucker A.W., editors, Advances in Game Theory, Princeton University Press, 443-476.

Catin, M. (1985), Effets externes : marché et système de décision collective, edt Cujas, Collection de la Faculté d'Economie Appliquée d'Aix-Marseille III.

Coase, R. (1960), "The problem of social cost", Journal of Law and Economics, Vol. 3, octobre: $1-44$.

Goetze, D. (1982), "A decentralized mechanism for siting hazardous waste disposal facilities", Public Choice, 39: 361-370.

Jeheil, P. and Molovanu B. (1995), "Negative externalities may cause delay in negotiation", Econometrica, Vol. 63, n 6 : 1321-1335.

Kunreuther, H. and Kleindorfer P.R. (1986), "A sealed-bid auction mechanism for siting noxious facilities", American Economic review, 1986, 76: 295-299.

Kunreuther, H., Kleindorfer P.R., Knez P.J. and Yarksick R. (1987), "A compensation mechanism for siting noxious facilities: theory and experimental design", Journal of environmental economics and management, 14: 371-383.

Kunreuther, H. and Portney P. (1991), "Wheel of fortune: a lottery/auction mechanism for siting of noxious facilities", Journal of Energy Engineering, Vol. 117, nº 3 : 125-132.

O'Hare, A. (1993), "Not on my block you don't: facility siting and public opposition", Public Policy, 1977, 25: 409-458.

O'Sullivan, A. (1993), "Volontary auctions for noxious facilities: incentives to participate and the efficiency of siting decision", Journal of Environmental Economics and Management, 1993, 25: 12-26.

Owen, G. (1995), Game theory, 2nd ed., Academic Press, 1995, Chap XII.

Schmeidler, M. (1969), "The nucleolus of a characteristic function game", SIAM Journal of applied Mathematics, 1969, 17: 1163-1170.

Schmeidler, M. (1994), The bargaining set, kernel and nucleolus, in R.J. Auman and S.Hart (ed.) Handbook of Game Theory with Economic Application, Vol II, North-Holland, 1994.

Siegel, S. and Castellan N.J. (1988) Nonparametric statistics for the behavioral sciences, 2nd ed., Mc Graw Hill.

Shapley, L.S. (1953), A value for n-person games, in Kuhn H.W. and A.W. Tucker (ed.), Contributions to the Theory of Games II. Annals of Mathematical Studies Series, 28, Princeton University Press, 307-317.

Sullivan, A.M. (1990), "Siting noxious facilities: A siting lottery with victim compensation", Journal of Urban Economics, 31: 360-374. 